\title{
UEMS MULTIDISCIPLINARY JOINT COMMITTEE IN PHLEBOLOGY - ROAD MAP
}

\author{
Jean-Jérome Guex', Fabrizio Mariani², and MJCP Members ${ }^{3}$ \\ 'President of Multidisciplinary Joint Committee in Phlebology \\ 2Secretary of Multidisciplinary Joint Committee in Phlebology \\ ${ }^{3}$ List of full members in document 1 in Appendix
}

EDITORIAL REVIEW

Phlebological Review 2015; 23, 4: 93-101 DOl: $10.5114 /$ pr.2015.59017

Submitted: 27.01 .2016

\begin{abstract}
This document's goal is to outline the current position of the Multidisciplinary Joint Committee in Phlebology (MJCP) in relation to the European recognition of phlebology and the Union Européenne des Médecins Spécialistes (UEMS) certification of phlebologists.

In addition, the desired education and acceptance of phlebology by the UEMS will be explained.

The MJCP was created by the UEMS Council meeting in April 2014 with the support of the UEMS sections of Dermatology, Surgery, Vascular Surgery and Radiology. The kick-off meeting of MJCP was held in Brussels, April 10 $0^{\text {th }}, 2015$ (MJCP Board in Appendix, doc. 1).
\end{abstract}

Key words: phlebology, venous chronic diseases, road map, European recognition of phlebology.

\author{
Accepted: 29.01.2016
}

\author{
ADDRESS FOR CORRESPONDENCE \\ Fabrizio Mariani MD, PhD, FACS \\ Secretary "Multidisciplinary Joint Committee \\ in Phlebology" UEMS \\ Angiomedica, loc. Belvedere - 53034 Colle \\ di Val d'Elsa \\ Siena, Italy \\ e-mail: brtma@tin.it
}

\author{
The Road Map for the European Recognition \\ of Phlebology \\ I. Phlebology - Definition \\ II. Chronic Venous Disorders - Relevance for Society \\ III. Education of the Phlebologist \\ IV. Certification of Phlebology \\ V. European Recognition of Phlebology \\ VI. Conclusions \\ VII. Appendix
}

\section{PHLEBOLOGY - DEFINITION}

Diagnosis and treatment of venous diseases is a multidisciplinary issue. Phlebology is the study of the anatomy, physiology, diseases and treatments of the veins. Complaints and clinical signs of chronic venous disorders (CVD) are related to disturbances of the macro- and microcirculation. Venous disorders concern mainly the lower legs, and they can be acute, e.g. superficial and/ or deep venous thrombosis, varicose vein bleeding, or chronic, e.g. varicose veins, post-thrombotic syndrome and venous malformations. The CEAP classification is a clinical classification method accepted worldwide, which was first developed in 1995 and revised in 2004. The CEAP classification describes Clinical classes (from 0 to 6), Etiology, Anatomy and Pathophysiology of CVD.

Venous symptoms may include tingling, aching, burning, pain, muscle cramps, swelling, sensations of throbbing or heaviness, itching skin, restless legs, leg tiredness, and/or fatigue. Although not pathognomonic, these may be suggestive of CVD, particularly if they are exacerbated by heat or worsen during the course of the day, and are relieved by leg rest and/or elevation. Clinical signs are varicose veins, telangiectasias, corona phlebectatica, oedema, hyperpigmentation, lipodermatosclerosis, white atrophy and leg ulcers. Overweight, obesity, occupational factors, hormones and hormonal treatments, and inherited and genetic factors seem to play an important role in phlebology. Patients with varicose veins usually have a positive family history for the disease, and in the analysis of deep vein thrombosis patients inherited thrombophilia risk factors are sometimes discovered. Some venous diseases are congenital, e.g. May-Thurner or Klippel-Trenaunay syndrome. Furthermore, diseases of the lymphatic system usually belong to the working area of phlebology.

Phlebology is practised mainly by angiologists/vascular physicians, internists, dermatologists and general/ vascular surgeons. The management of the phlebology patient demands not only extensive knowledge of the venous anatomy, pathophysiology and diseases, but also a combination of invasive and non-invasive diagnostic and therapeutic skills. The fact that phlebology in most countries does not exist as a distinct (sub) specialty, and the diversity of medical knowledge and skills that is needed to treat phlebology patients, explains why physicians of different specialties practise phlebology. This broad spectrum of medical doctors justifies the multidisciplinarity and a separate representation in the UEMS. 


\section{CHRONIC VENOUS DISORDERS - RELEVANCE FOR SOCIETY}

The incidence and prevalence of venous diseases are high. The incidence of varicose veins and CVD is $2 \%$ per year. Venous diseases are among the most common diseases all over Europe, with a prevalence of varicose veins of about 25\%, of chronic venous insufficiency (CVI, CEAP 3-6) of about $15 \%$ in the general population and of severe CVI with skin changes and venous ulcers $5 \%$ in the European adult population. Deep and superficial venous thrombosis are other frequent venous diseases. Therefore, the cost of management of venous diseases for society is significant.

One percent of the Western European population will develop a leg ulcer in their life. Diagnosis and treatment of venous leg ulcers represents up to $1-2 \%$ of the total healthcare budget in these countries, not calculating the indirect costs because of the loss of working days due to venous diseases. As the incidence of venous diseases increases with age, the need for phlebological care will increase in the near future due to the aging European population. Until 2050 the incidence of chronic venous diseases will increase by more than $20 \%$.

CVD may affect several aspects of quality of life (QoL). These functional effects are usually operationalized as (limitations in) physical, psychological, and social functioning. CVD can negatively affect patients' QoL, as it is a painful and disabling disease that can restrict physical functioning and mobility, and that is associated with depression, negative emotion and social isolation. Patients with venous leg ulceration or deep venous thrombosis report impairment of their physical functioning and mobility similar to patients suffering from congestive heart failure.

Skilled phlebologists can offer highly cost-effective treatments. Research on new diagnostic investigations such as duplex ultrasound and treatments such as endovenous thermal ablation techniques have been recently introduced and contribute to evidence-based treatments, with significantly lower costs than before. For example, phlebography and hospitalization have almost disappeared in varicose vein treatment. Good evidence-based phlebology will contribute to higher cost-effectiveness for this enormous medical and social burden.

\section{EDUCATION OF THE PHLEBOLOGIST}

The development of phlebology in the last decade with new antithrombotic drugs and new treatment options for varicose veins and CVD has changed the profession substantially. Nevertheless, phlebology is not well recognized in the European medical system. As an officially recognized subspecialisation it is only possible in Germany, Austria and Switzerland. In addition, phlebology is an interdisciplinary specialisation involving vascular surgeons, internists, vascular physicians (angiologists) and dermatologists in a similar way, not to forget radiologists, haematologists and other disciplines, who also have important roles. Because of the epidemiologic magnitude of the problem, general practitioners play a very important role in selecting patients for further diagnosis and treatment. There is a great need for a well-defined educational programme to educate phlebologists and to assure patients that they can obtain the best possible treatment from a registered phlebologist. A well-defined curriculum phlebology has been designed by the ECoP (European College of Phlebology - Maastricht, March $8^{\text {th }}$, 2015) and from the Union Internationale de Phlébologie (UIP), which has a worldwide coordinating role in the field of Phlebology. The Curriculum Phlebology (Appendix, doc. 2) will be discussed and approved by the MJCP Members to set up a uniform, high quality educational programme for Phlebology in Europe, consequently to certify the curriculum of Phlebologists.

\section{CERTIFICATION(S) OF PHLEBOLOGY}

As mentioned above, certification is mandatory to guarantee the highest level of knowledge. The UEMS is the only European body which is able to host this certification (European Council for Accreditation of Medical Specialist Qualifications [ECAMSQ], Council for European Specialist Medical Assessment [CESMA]). As the certification is open to a wide group of physicians with many different backgrounds, this certification will not create barriers and will serve only to guard the desired minimal levels of quality of care in phlebology. After founding a Multidisciplinary Joint Committee (MJC) on Phlebology within the UEMS, the institution of a Task Force "European Board of Certification of Phlebology $(\mathrm{EBCP})$ " is the second step to provide a European Certification of Phlebology. This is necessary to guarantee a high level of phlebological care for the EU community. Certification in phlebology in general is certainly the highest and ultimate aim of such a board, but progressively, certification in limited parts of the discipline (e.g. ultrasounds, endovenous procedures, chemical ablation, etc.) will be a sound procedure to build up the whole.

\section{EUROPEAN RECOGNITION OF PHLEBOLOGY}

The European Directive on recognition of professional qualifications (Directive 2005/36/EV of the European Parliament and of the Council on the recognition of professional qualifications as a particular medical competence in Europe in Annex 5.1.3.) does not identify phlebology as a medical speciality or sub-specialty. The European Union requires that, to become a specialty, it must be recognized in at least two fifths of the Member States and, at the same time, by a particular majority (a weighted vote that is determined by the population of each country and other factors and giving what is called 
a "qualified majority") in a committee on Qualification of the European Commission (not only for medical professions but generally for all protected professions).

Furthermore, to create a Specialist Section for Phlebology within the UEMS, phlebology has to be recognized as an independent speciality by more than one third of the EU Member States and must be registered in the Official Journal of the European Commission (Medical Directives).

These requirements for a primary speciality are not fulfilled for phlebology, and therefore the aim should be the incorporation of phlebology as a particular competence in the European Directives 2005/36/EV of the European Parliament and of the Council on the recognition of professional qualifications. This terminology is consistent with all forms of training based on acquisition of competencies.

In the survey of training programmes in different EU Member States the minimum duration of training in months for phlebology varies, but the median time in Europe is 24 months, e.g. in Germany, where phlebology is recognized as a sub-specialty (Appendix, doc. 3).

An important additional factor to consider is how the status of recognized phlebology may affect the quality of patient care. Current evidence indicates that patient outcomes are better when patients are cared for by trained phlebologists. In Europe this can be achieved by facilitating the acquisition of harmonized competencies in phlebology by trainees from a wide variety of primary specialty training programmes. This may also have the added benefit of optimizing the practice of phlebology.

\section{Specialty training and regulation in the European Union}

Medical specialties are represented at European level within the Union by the non-statutory body called the Union Européenne des Médecins Spécialistes UEMS (www.uems.eu), founded in 1958, which collaborates with the EU as the relevant body for harmonizing training and quality assurance. With a current membership from 37 countries, it is the representative organisation of the National Associations of Medical Specialists in the European Union and its associated countries. Its structure consists of a Council responsible for and working through 43 Specialist Sections and their European Boards, addressing training in their respective specialty and incorporating representatives from academia (societies, colleges and universities).

An Executive comprising the President, the Secretary-General, the Liaison Officer, and the Treasurer, is responsible for the routine functioning of the organisation.

The UEMS represents over 1.6 million medical specialists in all the different specialties. It also has strong links and relations with European institutions (Commission and Parliament), the other independent Euro- pean Medical Organisations and the European Medical/ Scientific Societies. By its agreed documents, UEMS sets standards for high quality healthcare practice that are transmitted to the authorities and institutions of the EU and the National Medical Associations, stimulating and encouraging them to implement its recommendations.

The UEMS has three branches: the Council, the National Medical Associations, the European Accreditation Council for Continuing Medical Education (EAC$\mathrm{CME}$ ), and the Specialty Sections, the Multidisciplinary Joint Committees (MJC) and the Boards (Explanatory Notes on the functioning of UEMS Specialist Sections, Divisions, Multidisciplinary Joint Committees, European Boards and Thematic Federations, August 2013, http:// www.uems.eu/aboutus/statutes). Each section is composed of national representatives elected by the National Medical Associations drawn from universities and professional organizations from each member country.

According to current UEMS rules, a medical discipline has the right to create a section if it is recognized as a specialty in more than one third of EU member states and is in the list of the official journal of the European Commission.

Each Section or MJC can create a European Board (part IV of the Explanatory Notes on the functioning of UEMS Specialist Sections, Divisions, Multidisciplinary Joint Committees, European Boards and Thematic Federations, August 2013, http://www.uems.eu/about-us/statutes), which is a working group, and which is composed of members of the section and of the scientific societies in the field. The Boards provide educational credits, harmonise training, and foster quality in medical education through visiting programmes.

\section{Establishing a European Board for Phlebology (EBP)}

In order to facilitate the harmonization of training in phlebology across Europe (Appendix, doc. 2), the Multidisciplinary Joint Committee in Phlebology (MJCP) can create a European Board for Phlebology, with representatives drawn from the MJCP and from the European Societies of Phlebology. The Board can thus accommodate all current national models of training. The MJCP will act as an executive committee for the Board, and provide a conduit for the Board to report to the council of the UEMS. All members of the Board will have a vote.

\section{CONCLUSIONS}

There is a great medical social and financial burden related to venous diseases. Well-educated physicians can only give best medical care. As many different medical specialties including dermatology and surgery are involved in daily phlebological practice, it is only realistic to cooperate, defining minimal requirements and 
creating an educational programme with UEMS labelled certification, to guarantee cost-effective, evidence-based phlebological care of the highest level in the EU. A Multidisciplinary Joint Committee in Phlebology in the UEMS can best achieve this goal.

\section{APPENDIX}

\section{Document 1}

MJC in Phlebology - Board

President Jean Jérôme Guex (France)

Secretary Fabrizio Mariani (Italy)

\section{Full Members}

Robert Strohal (Austria)

Matthias Hoke (Austria)

Marc Vuylsteke (Belgium)

Ivan Staelens (Belgium)

Jean-Claude Wautrecht (Belgium)

Lotte Klitfod (Denmark)

Claudine Hamel Desnos (France)

Ingo Flessenkaemper (Germany)

Knut Kroeger (Germany)

Spyros Vasdekis (Greece)

Dimitris Christopoulos (Greece)

Imre Bihari (Hungary)

Attila Szabo (Hungary)

Greg Fulton (Ireland)

Giampaolo Sozio (Italy)

Linas Velicka (Lithuania)

K.P. De Roos (Netherlands)

Marald Wikkeling (Netherlands)

Tomasz Zubilewicz (Poland)

Tomasz Urbanek (Poland)

José Pereira Albino (Portugal)

Armando Mansilha (Portugal)

M. Carmen Sălvăstru (Romania)

Pavel Poredos (Slovenia)

Jurg Traber (Switzerland)

\section{Document 2}

Phlebology in Europe (Belgium, Denmark, France, Germany, Greece, Italy, Netherlands, Poland, Switzerland) Summary Draft - MJC in Phlebology, October 2015

\section{Contents}

1. Education in Phlebology

2. Scientific Phlebological Societies

3. Guidelines

4. Reimbursement

5. Other considerations

6. Appendix - Table

\section{EDUCATION IN PHLEBOLOGY}

In Europe, phlebology does not have the status of a specialty. It is recognized as a subspecialisation (addi- tional training), only in Germany, Austria and Switzerland. Phlebologists are general practitioners, general and vascular surgeons, angiologists, vascular physicians, dermatologists, doctors in aesthetic medicine, plastic and reconstructive surgeons, and doctors in internal medicine. There are important differences between the countries concerning the specialisation of the physicians working in the field of phlebology - in some countries (e.g. Poland) most people come from the fields of vascular surgery (VS) and vascular medicine (VM), while in others (e.g. Germany) there is a high prevalence of dermatologists in this area. Taking into account the programmes of training in VM, VS or dermatology, there is still no unification of the specialisation programmes in Europe, which leads to potential differences in the training in phlebology between the countries.

The phlebology training in each country is part of the general training of a vascular surgeon, of a dermatologist (Germany, Switzerland, Netherlands) or a vascular physician (angiologist) in France.

Masters and courses organized by scientific societies or universities or even private organizations are available in all European countries, but there is not a real uniform, shared curriculum leading to phlebology.

In Germany, regulations differentiate the status of medical specialisation from subspecialisation and additional training. Phlebology has the status of additional training. There is a paper called Musterweiterbildungsordnung (MWBO), which is the base for all the WBO (regulations for postdoc education), which are only valid each for one out of sixteen Bundesländer (Provinces). In the WBO, times and contents of education in phlebology are regulated (the text is added to this draft). The subspecialisation of phlebology embraces prevention, recognition, treatment and rehabilitation of diseases and malformations of the venous system of the lower extremities, including thrombotic diseases. In addition, the German Society of Phlebology (DGP) has founded an academy for education and offers a curriculum for gaining phlebological competence and certifying this competence.

In contrast, to gain the level of proven additional training, which is a legal act, the training according to the DGP academy is a private activity.

Until now, French universities have taught vascular medicine (VM) by means of a DESC (diploma of complementary specialised studies) after the student has received a DES (diploma of specialised studies) for example in general medicine. The DESC in VM includes education in phlebology as well as in arterial and lymphatic diseases. It must be emphasized that all students in VM DESC receive a high level education and training in duplex ultrasound scanning. The DESC lasts two years and gives a hyper-specialisation in VM but does not entitle one to a specialty, either in VM nor in phlebology. There is no official specialty of VM or phlebology in France despite the existence of diplomas. If a new grad- 
uate in VM wants to aim his activity toward phlebology, the possibility exists to enhance his knowledge thanks to several university diplomas including one in phlebology (Paris VI). This is optional for vascular physicians, but the French high authority for health (HAS) requires special knowledge and training for physicians wishing to practise endovascular procedures. However, from 2017, a speciality of vascular medicine (DES of Vascular Medicine) will be created in France, with a university education of 4 years. This speciality will have a common-core syllabus for the first year with the cardiology.

In Greece, phlebology is practised mainly by vascular surgeons, and the training involves all aspects of venous diseases (thrombosis, varicose veins, etc.). The majority of young vascular surgeons participate in the FEBVS "Fellow of the European Board in Vascular Surgery" examinations.

Additionally, a 6-month training programme for vascular ultrasound, supervised by the Ministry of Health, is offered to vascular surgeons who need an official certification for ultrasound practice. This programme is run in three University Hospitals of the country where the vascular departments have the necessary facilities.

In the Netherlands, phlebology is still not a separate specialty, but it has been incorporated in the training of Dutch dermatologists since the 1985. Phlebology is also incorporated in the surgical training for the residents with an examination during this course. For vascular surgeons in training the FEBVS "Fellow of the European Board in Vascular Surgery" is mandatory. The Section and Board of Vascular Surgery has defined the specialty of vascular surgery as "the clinical and scientific discipline concerned with the diagnosis, treatment and prevention of diseases affecting arteries, veins and lymphatics".

In Switzerland, to obtain the certificate of competence in phlebology candidates have to complete the curriculum in phlebology which has been developed by the SGP (Schweizerische Gesellschaft für Phlebologie) and is supervised by the SIWF (Schweizerisches Institut für ärztliche Weiter- und Fortbildung). The curriculum encourages all theoretical aspects in phlebology and the various diagnostic and treatment options.

A formal condition for the acquisition of the certificate in phlebology is completion of medical specialist training. The final audit includes a written multiple choice part, and an oral examination in the subsequent 9 weeks in one of the competence centres or selected specialized institutions. After a 3-year period phlebologists have to confirm an adequate further education (at least 36 hours of specific and certificated training) to renew the certificate in phlebology for another 3-year period.

In Italy and in Poland, the Italian College of Phlebology and the Polish Society of Phlebology introduced a system of certification (Certificate in Phlebology) based on the previous training, experience and the number and kind of performed phlebological interventions (including ulcer treatment, compression therapy, sclerotherapy and other kinds of interventions). To maintain the certificate there is a need for continuous education based on participation in conferences and courses, phlebological journal subscriptions and conference report presentations or publication of papers (certificate is valid for 2 years).

\section{SCIENTIFIC PHLEBOLOGICAL SOCIETIES}

The National European Phlebological Societies are: Austria

- Austrian Society of Phlebology and Dermatology Angiology

Balkan countries

- Balkan Venous Forum

- Baltic Countries

- Baltic Society of Phlebology

Benelux

- Benelux Society of Phlebology

Bulgaria

- Bulgarian Society of Phlebology

Croatia

- Croatian Society of Phlebology

Czech Republic

- Czech Society of Phlebology

France

- French Society of Phlebology (SFP)

Germany

- German Society of Phlebology (DGP)

Greece

- Hellenic Phlebological Society

Hungary

- Hungarian Venous Forum

Italy

- Italian Association of Phlebology (AFI)

- Italian College of Phlebology (CIF)

- Italian Society of Phlebology (SIF)

Netherlands

- Dutch College of Phlebology

Poland

- Polish Phlebological Society

Portugal

- Phlebological Section of the Portuguese Society of Cardiothoracic and Vascular Surgery

- Portuguese Society of Angiology and Vascular Surgery

- Portuguese Society of Surgery, Chapter of Venous Surgery

\section{Romania}

- Romanian Society of Phlebology

\section{Serbia}

- Serbian College of Phlebology

Spain

- Spanish Chapter of Phlebology and Lymphology

\section{Switzerland}

- Swiss Society of Phlebology 


\author{
Scandinavia \\ - Scandinavian Venous Forum \\ Turkey \\ - Turkish Society of Phlebology \\ United Kingdom \\ - Venous Forum of the Royal Society of Medicine
}

There are two other European Phlebological Societies: the European Venous Forum EVF (the EVF is an all-European Society with personal membership), the European College of Phlebology (ECoP) (a union of phlebological societies in Europe). Others societies more devoted to VM or VS but including Phlebology are the Société Française de Médecine Vasculaire, the Société Française d'Angéiologie, which is more multidisciplinary, the Italian Society of Angiology and Vascular Pathology, and all the national societies of VS. Some societies in Europe are devoted to the knowledge and care of leg ulcers, e.g. European Wounds Medical Associations, Italian Association of Cutaneous Ulcers, and others. The International Compression Club (ICC) and the Compression Therapy study Group (CTG) are devoted to compression therapy.

The number of members of the phlebological societies is approximately 10000 .

The majority of the phlebological societies are affiliated to the International Union of Phlebology (UIP), founded in 1959.

\section{GUIDELINES}

1. Agus G.B., Allegra C., Arpaia G., Gasbarro V., De Franciscis S. Coll. Mariani F., et al. Guidelines Italian College of Phlebology. Int Angiol 2013; 32, suppl. 1-n 4.

2. Nederlandse Vereniging voor Dermatologie en Venereologie (NVDV), Richtlijn Varices \& Diep veneuze ziekte, 2013.

3. Rabe E., Breu F.X., Cavezzi A., Coleridge Smith P., Frullini A., Gillet J.L., Guex J.J., Hamel-Desnos C., Kern P., Partsch B., Ramelet A.A., Tessari L., Pannier F.; Guideline Group. European guidelines for sclerotherapy in chronic venous disorders. Phlebology 2014; 9: 338-354.

4. Mariani F. (ed.). Compression. Consensus Document based on Scientific Evidence and Clinical Experiences. Minerva Medica, Torino 2009.

5. Maessen-Visch M.B., de Roos K.P. Dutch Venous Ulcer guideline update. Phlebology 2014; 29 (1 suppl): 153 156.

6. NICE clinical guideline 168. Varicose veins in the legs. The diagnosis and management of varicose veins. Issued: July 2013.

7. Wittens C., Davies A.H., Bækgaard N., Broholm R., Cavezzi A., Chastanet S., de Wolf M., Eggen C., Giannoukas A., Gohel M., Kakkos S., Lawson J., Noppeney T.,Onida S., Pittaluga P., Thomis S., Toonder I., Vuylsteke M., Kolh P., de Borst G.J., Chakfé N., Debus S., Hinchliffe R., Koncar I., Lindholt J., de Ceniga M.V.,
Vermassen F.,Verzini F., De Maeseneer M.G., Blomgren L., Hartung O., Kalodiki E., Korten E., Lugli M., Naylor R., Nicolini P., Rosales A.; European Society for Vascular Surgery. Management of Chronic Venous Disease, European Journal of Vascular and Editor's Choice - Management of Chronic Venous Disease: Clinical Practice Guidelines of the European Society for Vascular Surgery (ESVS). Eur J Vasc Endovasc Surg 2015; 49: 678-737.

8. Zawilska K., Bała M.M., Błędowski P., Chmielewski D.W., Dobrowolski Z., Frączek M., Frołow M., Gajewski P., Guzik T., Jaeschke R., Korman T., Kotarski J., Kozubski W., Krawczyk M., Kruszewski W., Kulikowski J., Kutaj-Wąsikowska H., Mayzner-Zawadzka E., Mrozikiewicz P.M., Musiał J., Niżankowski R., Pasierski T., Poręba R., Tomkowski W., Torbicki A., Undas A., Urbanek T., Wojtukiewicz M.Z., Woroń J., Wroński J.; Working Group from the Anticoagulation and Thrombolytic ACCP Conference. Polish guidelines for the prevention and treatment of venous thromboembolism. 2012 update. Pol Arch Med Wewn 2012; 122 Suppl 2: 3-74.

9. The guidelines of the German Society of Phlebology (DGP, 2008) are:

- Leitlinie zur Diagnostik und Therapie der Krampfadererkrankung

- DGP und DEGAM gemeinsam erstellte Kurzversion zum Ulcus cruris venosum

- Diagnostik und Therapie der Venenthrombose und der Lungenembolie

- Leitlinie: Lipödem der Beine

- Leitlinie: Phlebologischer Kompressionsverband (PKV)

- Prophylaxe der venösen Thromboembolie (VTE)

- Diagnostik und Therapie des Ulcus cruris venosum

- Leitlinie: Sklerosierungsbehandlung der Varikose

- Leitlinie: Venöse Diagnostik mit der Venenverschlußplethysmographie mittels

- Dehnungsmeßstreifen

- Leitlinie: Venöse Diagnostik mit der Phlebodynamometrie

- Leitlinie: Diagnostik und Therapie der Chronischen Venösen Insuffizienz (CVI)

- Leitlinie zur venösen Diagnostik mit der Licht-Reflexions-Rheographie/Photoplethysmographie

- Leitlinie: Leitlinie zur Diagnostik und Therapie der Thrombophlebitis superficialis

- Leitlinie: Medizinischer Thromboseprophylaxe-Strumpf (MTS)

- Leitlinie: Intermittierende pneumatische Kompression (IPK oder AIK)

- Leitlinie: Medizinischer Kompressionsstrumpf (MKS)

\section{REIMBURSEMENT}

The public reimbursement for phlebological procedures covers vascular phlebological visits, duplex scans and varicose vein open surgical procedures in most Euro- 
pean countries. The surgical procedures apply to varicose veins referred to as $\mathrm{C} 2-\mathrm{C} 6$ in the $\mathrm{CEAP}$ classification used for varicose veins. Usually they do not apply to varicose veins referred to as $\mathrm{C} 0$ and $\mathrm{C} 1$ in the CEAP classification. As a rule the treatment of these varicose veins is not an insurable provision under the health insurance (public and private) because these are generally cosmetic interventions.

In the United Kingdom only the procedures for venous chronic insufficiency in C4-C6 and for venous thrombotic diseases are reimbursed; to be eligible for treatment in most areas, patients need to have varicose veins with complications such as ulcers, phlebitis, bleeding or skin changes such as lipodermatosclerosis or varicose eczema.

Endovenous laser treatment (EVLT), radiofrequency ablation (RFA), elastic stockings and sclerotherapy are not covered by the public reimbursement in all European countries.

In France, DUS mapping is reimbursed around $€ 75$. Sclerotherapy of varicose veins is reimbursed around $€ 30$, US guided foam sclerotherapy around $€ 40$. Fees for stripping are around $€ 130$ (plus hospital expenses) and $€ 190$ for thermal ablation.

In Italy, reimbursement for varicose vein open surgery is regulated by the public DRG system, and the fees for the doctors are around $€ 135, € 270$ for non-resident patients (coming from other Italian regions), and $€ 410$ for the surgical treatment of leg ulcers. In most cases, EVLT, RFA and sclerotherapy procedures are paid for out-of-pocket by the patient or they are reimbursed by private medical insurances. In some regions of Italy reimbursement of EVTA is expected in an outpatient setting, as reimbursement of services provided in the regional health care office based on the actual diversity of content and recognized clinical validity. This treatment is supplied as a clinical pathway including the preoperative anaesthesia visit, the anaesthesia, preoperative blood tests, surgical procedure, medication and post-operative check-up with possible removal of stitches. They are also considered benefits payable only at clinics protected, or at clinics located within a public or accredited private hospital. Italian regions where there is a rate of reimbursement for EVTA are Lazio, Veneto, Marche and the province of Bolzano The rate of reimbursement varies widely, ranging from $€ 400$ in Lazio to $€ 1334$ in Marche, with $€ 833$ in Veneto and $€ 765$ in Bolzano. In all regions where it is expected, reimbursement for EVTA is paid only for endovenous laser ablation and the amount of the refund is always less than the reimbursement for the saphenectomy surgical procedure performed in the same care setting, except in the region of Marche, where the refund for EVTA is higher than the reimbursement for surgical saphenectomy.

Doctors' fees may be higher with optional reimbursement by complementary medical insurances.

\section{OTHER CONSIDERATIONS}

Duplex ultrasound (DUS) is not carried out by technicians, only by physicians (or surgeons). Venous DUS is done above all by vascular physicians. However, recently a broad spectrum of medical doctors are consulting and treating venous patients in dedicated phlebological centres and private offices, as the effect of the current health situation and the increasing demands of patients as well as current guidelines emphasizing the role of preoperative or preprocedural DUS evaluation. In most countries it is becoming the practical standard of care, even if DUS is not involved in many specialisation programmes. Some radiologists or cardiologists with different degrees of specific education also perform venous DUS; in this case, they mainly perform DUS of deep veins; however, they do not manage phlebology treatments. Sclerotherapy treatments are mostly done by phlebologists, vascular physicians, dermatologists, and doctors in aesthetic medicine. An increasing number of them also carry out EVLT and RF. Very few carry out classical varicose surgery. Surgery, including stripping, is mostly reserved for surgeons, vascular or general; some of them practise EVLT, RF and sclerotherapy. In France there is a trade association for vascular physicians, the SNMV (Syndicat National des Médecins Vasculaires), which has over 1,300 members.

\section{Document 3}

Curriculum Phlebology

E. Rabe, C. Wittens, M. Neumann, A. Davies

Approved by the European College of Phlebology (ECoP), Maastricht, March $8^{\text {th }}, 2015$

\section{Definition}

Phlebology includes prevention, diagnosis, treatment and rehabilitation of patients with venous diseases and venous malformations.

\section{Knowledge and clinical experience}

A phlebologist must have knowledge and clinical experience in different components of the discipline.

This includes:

- Basic sciences

- Clinical sciences

- Diagnostic evaluation

- Treatment

- Other competences

2.1. Basic sciences: Knowledge and clinical experience in:

- Anatomy of the vascular system

- Embryology of the vascular system

- Genetics of venous and lymphatic diseases

- Physiology and pathophysiology of the venous and lymphatic system

- Histology and histopathology of venous diseases

- Wounds and wound healing

- Differential diagnosis of skin changes of the extremities 


\section{SUMMARY TABLE}

\begin{tabular}{|c|c|c|c|c|c|c|}
\hline Country & Speciality & Subspecialty & Curriculum training & Others & Guidelines & PR \\
\hline Belgium & no & no & $\begin{array}{l}\text { D } \\
\text { VS }\end{array}$ & & yes & yes \\
\hline Denmark & no & no & $\begin{array}{l}\text { D } \\
\text { VS }\end{array}$ & & yes & yes \\
\hline France & no & no & $\begin{array}{c}\text { VM / DESC } \\
\text { Diplome University Paris VI } \\
\text { HAS certification }\end{array}$ & SNMV & yes & yes \\
\hline Germany & no & yes & $\begin{array}{c}\text { WBO } \\
\text { Certification DGP }\end{array}$ & $\begin{array}{c}\text { DGP } \\
\text { Academy }\end{array}$ & yes & yes \\
\hline Greece & no & no & $\begin{array}{c}\text { VS } \\
\text { UM } \\
\text { vu Diplome (VS) }\end{array}$ & $\begin{array}{l}\text { HPS } \\
\text { Courses }\end{array}$ & no & $\begin{array}{l}\text { yes } \\
\text { (nat) }\end{array}$ \\
\hline Italy & no & no & $\begin{array}{c}\text { VS } \\
\text { UM } \\
\text { CIF certification }\end{array}$ & & yes & $\begin{array}{l}\text { yes } \\
\text { (nat) }\end{array}$ \\
\hline Netherlands & no & no & $\begin{array}{l}\text { D } \\
\text { VS } \\
\text { UM }\end{array}$ & $\begin{array}{c}\text { DCP } \\
\text { Training } \\
\text { Programme }\end{array}$ & yes & yes \\
\hline Poland & no & no & $\begin{array}{c}\text { VM } \\
\text { VS } \\
\text { PSP certification }\end{array}$ & & yes & $\begin{array}{l}\text { yes } \\
\text { (nat) }\end{array}$ \\
\hline Switzerland & no & yes & $\begin{array}{c}\text { SIWF } \\
\text { Certification SGP }\end{array}$ & & no & $\begin{array}{l}\text { yes } \\
\text { (Ins) }\end{array}$ \\
\hline
\end{tabular}

Ins - insurance system; D - dermatology; DESC - diploma of complementary specialized studies; DCP - Dutch College of Phlebology; DGP - German Society of Phlebology; CIF - Italian College of Phlebology; nat - not all the treatments; HAS - French High Authority for Health; HPS - Hellenic Phlebological Society; PR - Public Reimbursement; PSP - Polish Society of Phlebology; SNMV - Syndicat National des Médecins Vasculaires; SGP - Swiss Society of Phlebology; UM - University Master; VM - vascular medicine; VS - vascular surgery; WBO - regulations for postdoc education; VU - venous ultrasound

- Thromboembolic diseases

- Coagulation and anticoagulation

- Pharmacology

- Basic physical principles of diagnostic and therapeutic tools

2.2. Clinical sciences: Knowledge and/or clinical experience in:

- Superficial venous incompetence

- Deep venous incompetence

- Perforator incompetence

- Chronic venous insufficiency

- Pelvic venous insufficiency

- Functional venous insufficiency

- Lymphatic incompetence

- Venous thromboembolism

- Venous obstruction and compression

- Venous malformations

- Venous tumours

- Vascular emergencies

- Differential diagnosis of signs and symptoms of venous diseases

\subsection{Diagnostic evaluation: Knowledge and clinical expe-} rience in:

- History taking

- Physical examination

- Differential diagnosis of venous signs and symptoms

- Ultrasound and Doppler evaluation of veins and arteries and sonography, including duplex and triplex

- Dynamic venous function tests

- Oedema assessment

- Venous thromboembolism diagnosis

- Disease classification

- Severity scoring systems

- Quality of life assessment

- Patient-reported outcome evaluation Knowledge of principles, indications and assessment in

- Magnetic resonance imaging (MRI)

- Computed tomography (CT)

- Contrast venography

- Laboratory tests

2.4. Treatment: Knowledge and clinical experience in:

- Counselling of life style, behaviour and diet 
- Compression therapy

- Pharmacological treatment of chronic venous diseases

- Wound care

- Sclerotherapy

- Endovenous ablation

- Transcutaneous venous ablation

- Venous thromboembolic diseases and conservative therapy

- Treatment of venous emergencies and complications

- Knowledge of principles, indications and assessment in

- Venous surgery of superficial veins and deep veins

- Endovascular embolisation

- Pelvic venous disorders

- Venous thromboembolic diseases of invasive therapy

- Deep venous obstruction

- Anaesthetic procedures in venous therapy

\subsection{Other competences}

- Epidemiology

- Evidence-based medicine

- Evaluation of study results

General recommendations:

1. Two years of clinical education in a certified institution with personal experience in an adequate number of procedures of the above listed items seems to be adequate to gain personal knowledge, clinical experience and personal skills as preconditions to become a phlebologist.

2. Accredited courses providing essential knowledge on basic and clinical sciences, superficial and deep venous interventions, sclerotherapy, DVT diagnosis and treatment, Doppler and duplex investigations, compression and ulcer treatment combined with a number of clinical procedures and a European examination can also be a precondition to qualify as a phlebologist.

These recommendations are based on:

1. Parsi K., Zimmet S., Allegra C., Bergan J., Gasparis A.P., Labropoulos N., Lee B.B., Malouf G.M., Partsch H., Rabe E., Ramelet A.A., Schadeck M., Vin F.; International Union of Phlebology. Phlebology training curriculum. A consensus document of the International Union of Phlebology (UIP)-2010. Int Angiol 2010; 29: 533-559.

2.ZimmetS.E., Min R.J.,Comerota A.J., Meissner M.H., Carman T.L., Rathbun S.W., Jaff M.R., Wakefield T.W., Feied C.F. Core content for training in venous and lymphatic medicine. Phlebology 2014; 29: 587-593.

Approved in Warsaw, Hotel Mercure - Krucza 28,

Olympus Hall III, October $17^{\text {th }} 2015$

Jean Jérôme Guex - President MJCP

Fabrizio Mariani - General Secretary MJCP 